\title{
An ounce of prevention - The new wave in HIV therapy
}

$\mathrm{I}_{\mathrm{s}}^{\mathrm{N}}$

N THE EARLY YEARS OF THE ACQUIRED IMMUNE DEFICIENCY syndrome (AIDS) era, patient management consisted of treating human immunodeficiency virus (HIV)-associated complications. Although this remains an important part of AIDS care, there has been an emerging trend towards secondary and primary prevention of major HIV-associated complications. Preliminary studies have suggested prophylactic therapy to be beneficial for Pneumocystis carinii pneumonia (PCP), tuberculosis, Mycobacterium avium complex (MAC) infection, toxoplasmosis, cryptococcosis and cytomegalovirus (CMV) retinitis.

\section{PNEUMOCYSTIS CARINII PNEUMONIA}

On June 16, 1989, the Centers for Disease Control (CDC) published guidelines for secondary prophylaxis for patients with previous PCP and primary prophylaxis for patients with a CD4 lymphocyte count less than 200 $\times 10^{6} / \mathrm{L}$ or those whose CD4 cells represent less than $20 \%$ of the total lymphocyte population (1).

The CDC guidelines recommend either trimethoprim-sulfamethoxazole (TMP-SMZ) or aerosolized pentamidine (AP). However, a recent trial comparing TMP-SMZ, one double strength tablet daily, to AP, 300 mg every four weeks via Respirgard II jet nebulizer (Marquest, Englewood, CO) AIDS Clinical Trial Group (ACTG021), was stopped by the data and safety monitoring board. Twenty-three centres enrolled 310 patients with previous PCP with a mean CD4 count of $56 \times 10^{6} / \mathrm{L}$. The trial was terminated after $50 \mathrm{PCP}$ recurrences: 14 on TMP-SMZ and 36 on $\mathrm{AP}$. The projected failure rate at 12 months was $4.5 \%$ for TMP-SMZ and $18.5 \%$ for AP.

This study suggests that TMP-SMZ, which is much less expensive than AP, should be the initial PCP regimen of choice for secondary prophylaxis. The regimen of choice in patients intolerant of TMP-SMZ is less clear. While AP is effective, it may be argued that dapsone with or without TMP is preferred because both are less expensive than AP and since TMP plus dapsone is as effective as TMP-SMZ in treating PCP (2).

\section{MYCOBACTERIUM TUBERCULOSIS}

Isoniazid preventive therapy is recommended for tuberculin-positive HIV-infected patients (defined as more than $5 \mathrm{~mm}$ induration) (3).

\section{MYCOBACTERIUM AVIUM COMPLEX}

Recently, a trial comparing rifabutin $300 \mathrm{mg} /$ day versus placebo for primary prevention of MAC bacteremia in AIDS patients with a CD4 lymphocyte count below $200 \times 10^{6} / \mathrm{L}$ was stopped by the data and safety monitoring board, since rifabutin significantly reduced the incidence of MAC bacteremia. A similar trial in San Francisco using clofazimine alone showed no efficacy (unpublished data). A trial evaluating clarithromycin 
for the prevention of MAC bacteremia is about to start in the United States (ACTG196).

\section{TOXOPLASMOSIS}

Cerebral toxoplasmosis occurs in approximately $30 \%$ of toxoplasma-seropositive, HIV-infected individuals. Secondary prophylaxis is an accepted part of management (4). Although a clinical trial of primary prophylaxis in such patients has not been performed, decision analysis has concluded that such therapy probably saves lives (5). It is possible that PCP prophylaxis regimens containing TMP with SMZ or dapsone will prevent toxoplasmosis.

\section{CRYPTOCOCCOSIS}

Cryptococcosis occurs in 5 to $10 \%$ of AIDs patients (6). It is currently not possible to identify patients at risk for this infection and although fluconazole is effective for secondary prophylaxis of cryptococcosis (7), primary prophylaxis cannot be recommended at present. However, the probable efficacy of fluconazole in primary prevention of cryptococcosis is one of several reasons for preferring fluconazole to ketoconazole when oral azole therapy is required for candidiasis.

\section{CYTOMEGALOVIRUS DISEASE}

Symptomatic CMV disease occurs in up to $20 \%$ of AIDS patients, with retinitis being more common than gastrointestinal disease. Secondary prophylaxis of CMV retinitis is standard practice (8). There presently is no evidence supporting the use of primary prophylaxis to prevent CMV disease. However, there is one study in bone marrow transplantation (9) and a second in renal transplantation (10) indicating some efficacy for high dose oral acyclovir in preventing CMV disease. Oral acyclovir is not an ideal therapy for CMV infection because of its poor activity against CMV and its poor oral bioavailability.

Within the next five years there likely will be an orally absorbed agent with reasonable anti-CMV activity and, primary prevention of CMV disease in HIV-infected patients will be achieved.

\section{LYMPHOMA}

As AIDS patients live longer, the incidence of AIDS-associated lymphoma has increased (11). Most of these lymphomas contain Epstein-Barr virus (EBV) genomic material (12). It is conceivable that an anti-EBV drug would decrease the incidence of HIV-associated lymphoma. If effective orally administered anti-CMV drugs are developed and if the same drugs have significant anti-EBV activity as well, they may reduce the incidence of HIV-associated lymphoma.

\section{SUMMARY}

We have entered an era of prevention of HIV-associated opportunistic infections. Primary prevention currently is recommended for PCP and tuberculosis. Secondary prevention is standard for cryptococcosis, toxoplasmosis and CMV retinitis. Recently, primary prevention of MAC bacteremia has been achieved. It is likely that primary prevention of toxoplasmosis is effective. It is speculated that orally absorbed drugs with reasonable activity against CMV and EBV will be available and offer primary prevention of disease due to these viruses.

\section{REFERENCES}

1. Masur H, Allegra C, Armstrong D, et al. Guidelines for prophylaxis against Pneumocystis carinii pneumonia for persons infected with human immunodeficiency virus. MMWR 1989;38:1-9.

2. Medina I, Mills J, Leoung C, et al. Oral therapy for Pneumocystis carninii pneumonia in the acquired immunodeficiency syndrome. A controlled trial of trimethoprim-sulfamethoxazole versus trimethoprimdapsone. N Engl J Med 1990;323:776-82.

3. Purified protein derivative (PPD)-tuberculin anergy and HIV infection: Guidelines for anergy testing and management of anergic persons at risk of tuberculosis. MMWR 1991;40(RR-5):27-32.

4. Israelski DM, Remington JS. Toxoplasmic encephalitis in patients with AIDS. Infect Dis Clin North Am 1988:2:429-45.

5. Rose DN. Prevention of toxoplasma activation among immunocompromised patients: A decision analysis. Presented at the VIth International Conference on AIDS, 1990. (Abst)

6. Dismukes WE. Cryptococcai meningitis in patients with AIDS. J Infect Dis 1988:157:624-8.

7. Bozzette SA, Larsen RA, Chill J, et al. A placebocontrolled trial of maintenence therapy wth fluconazole after treatment of cryptococcal meningitis in the acquired immunodeficiency syndrome. N Engl J Med 1991;324:580-4

8. Jacobson MA, Mills J. Serious cytomegalovirus disease in the acquired immunodeficiency syndrome (AIDS). Ann Intern Med 1988; 108:585-94.

9. Meyers JD, Reed EC, Shepp DH, et al. Acyclovir for prevention of cytomegalovirus infection and disease after allogeneic marrow transplantation. N Engl J Med 1988:318:70-5.

10. Balfour HH Jr, Chase BA, Stapelton JT, Simmons RL, Fryd DS. A randomized, placebo-controlled trial of oral acyclovir for the prevention of cytomegalovirus disease in recipients of renal allografts. $\mathrm{N}$ Engl $\mathrm{J}$ Med 1989:320:1381-7.

11. Opportunistic non-Hodgkin's lymphomas among severely immunocompromised HIV-infected patients surviving for prolonged periods on antiretroviral therapy - United States. MMWR 1991;40:591-600.

12. Anon. Epstein-Barr virus and AIDS- associated lymphomas. Lancet 1991:338:979-81. (Edit)

SD Shafran, MD, FRCPC

Edmonton, Alberta

JM Conly, MD, FRCPC

Saskatoon, Saskatchewan 


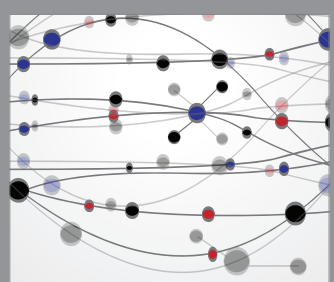

The Scientific World Journal
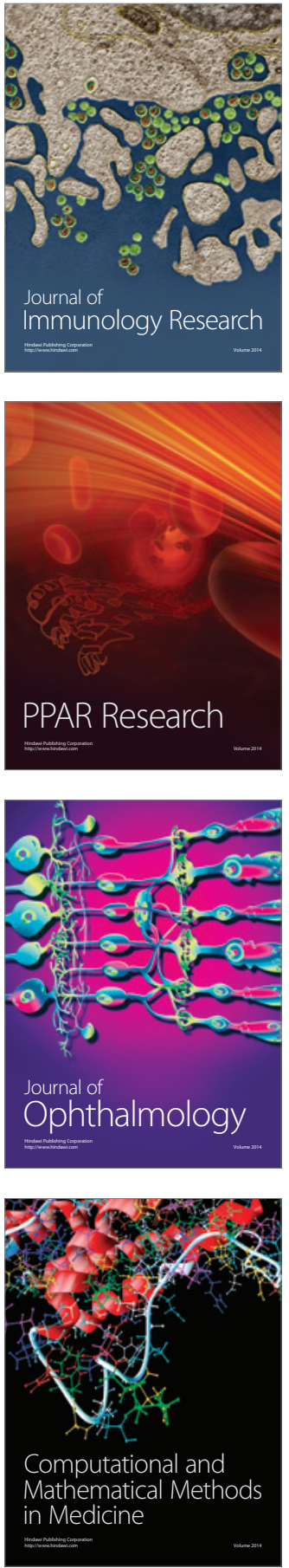

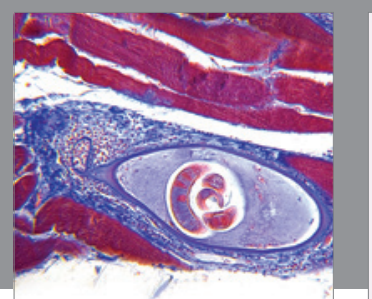

Gastroenterology Research and Practice

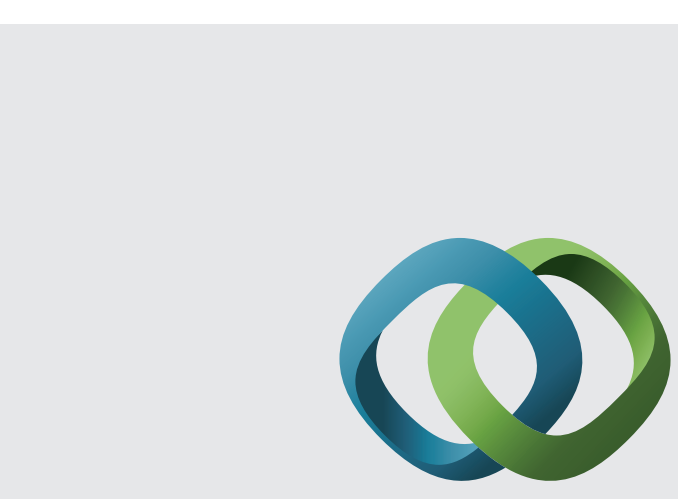

\section{Hindawi}

Submit your manuscripts at

http://www.hindawi.com
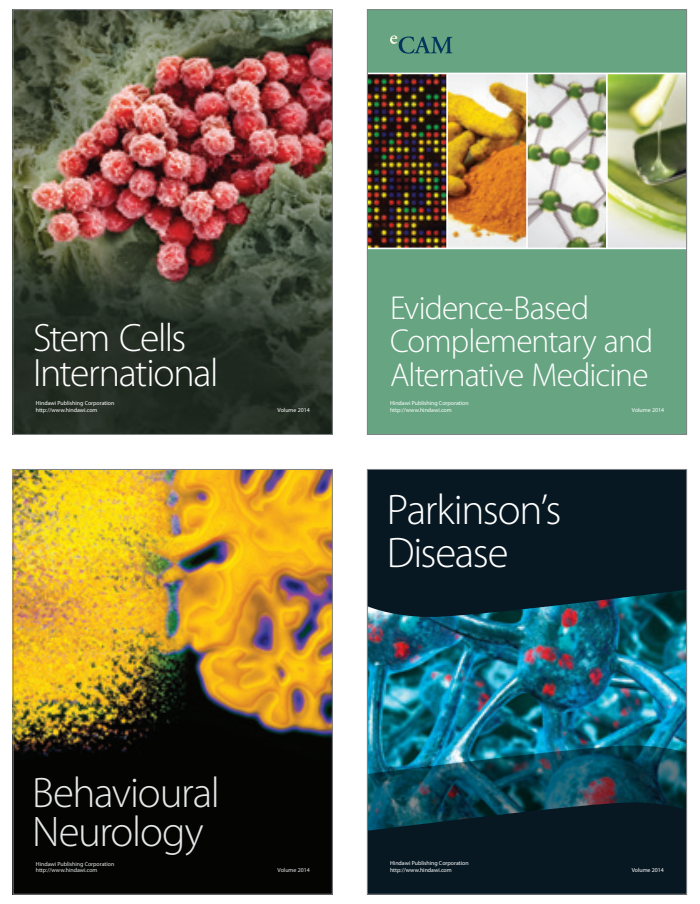
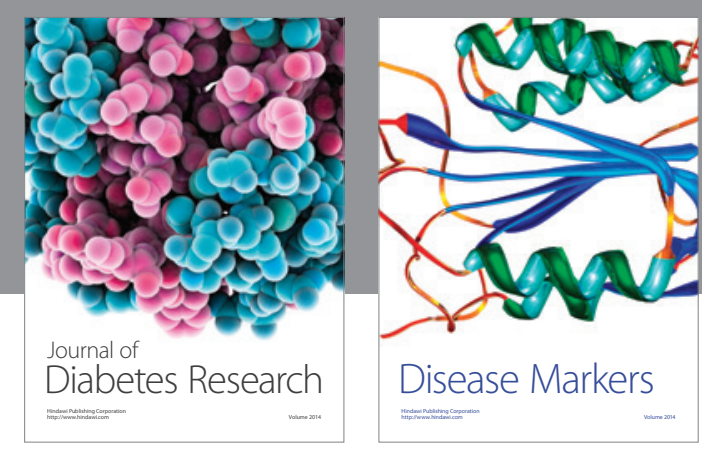

Disease Markers
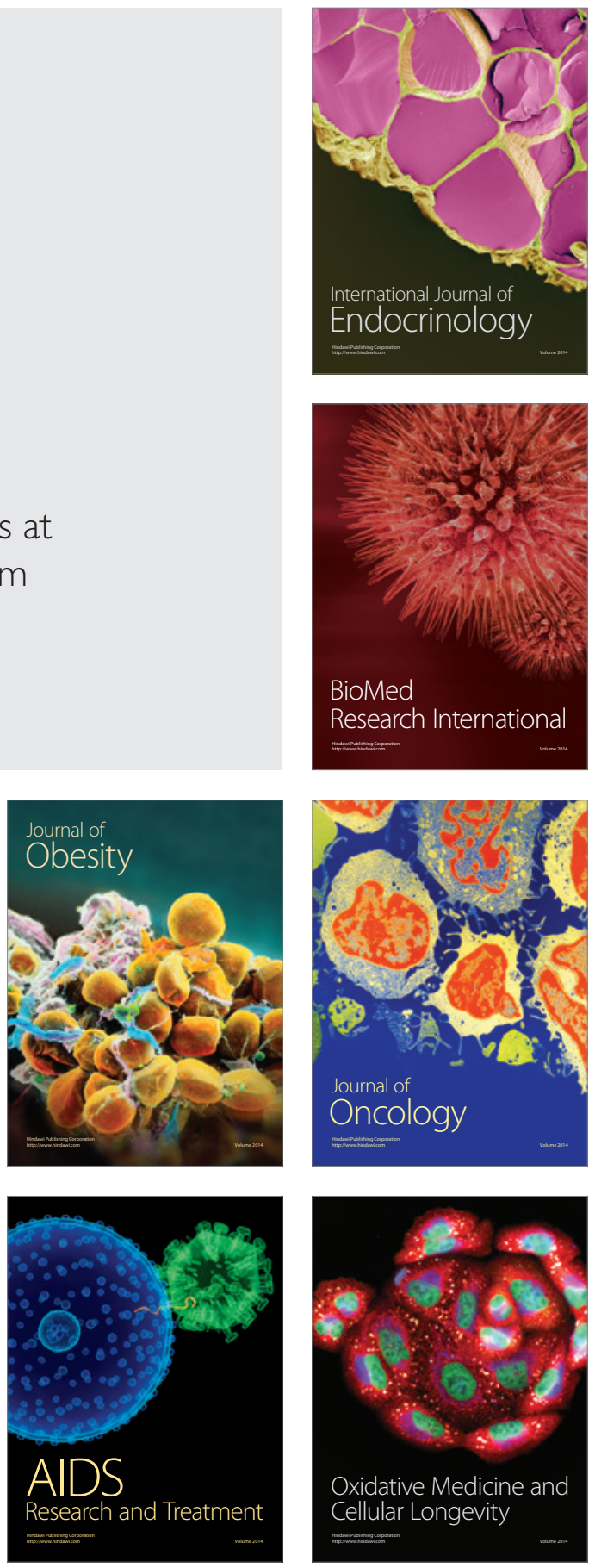